\title{
Green Public Spheres and the Green Governance State: the Politics of Emancipation and Ecological Conditionality
}

\author{
Timothy Doyle ${ }^{1 *}$ and Brian Doherty** \\ * School of History and Politics, University of Adelaide, Australia \\ ** School of Politics, International Relations and Philosophy, Keele University
}

This is an electronic version of an article published in Environmental Politics

Volume 15, Issue 5, 2006, pp.881-892.

Special Issue: Beyond Borders: Environmental Movements and Transnational Politics

Environmental Politics is available online at:

http://www.tandfonline.com/doi/abs/10.1080/09644010600937504

\section{$\underline{\text { Abstract }}$}

A consistent thread weaves through all the articles in this edition. Each author, in some fashion, reflects upon the dual concepts of a 'global green public sphere' and the 'global governance state', as they intersect with the politics of environmentalism. Indeed, as is evidenced in the preceding pages, the politics of green concern transmute into a myriad of different collective forms. Despite this diversity of responses found within and between environmental groups, we conclude that most greens cross boundaries in a positive fashion. Through the construction of transnational networks of solidarity, movements become global entities, acting in concert to protect ecosystems and emancipate humans and non-humans from degradation and subjugation and expanding the public sphere of green debate transnationally. In certain instances, however, environmentalism, is used as a tool for continued conquest and domination. These instances, though not generally reflective of green movements as a whole, are often writ large due to the relative power, in comparative terms, of the proponents. 'Environment', therefore can be either a symbol for liberation or repression; emancipation or conditionality. It can be used to support democracy or, alternatively, to support authoritarianism; it can be used to attack neoliberalism and corporate-controlled globalisation, and it can be used to support it; it can be used to

\footnotetext{
${ }^{1}$ Correspondence address: Timothy Doyle, School of History and Politics at the University of Adelaide, South Australia 5005, Australia. From January 2007, School of Politics, International Relations and Philosophy, Keele University, ST5 5BG United Kingdom. timothy.doyle@adelaide.edu.au
} 
lionise concepts of 'the local', and it can be utilised to denigrate local systems of meaning in a neo-colonial fashion.

\section{$\underline{\text { Introduction }}$}

There may be some intrinsic characteristics of environmental movements which allow them to range so freely across and within traditional geopolitical divisions. First, as Duffy argues in this collection, 'Since environmental problems are often transboundary, they have become an important arena for the development of transnational networks to manage them (this volume). In this light, it may simply be that environmental ills determine, to an extent, that transboundary crossings must be made. There is no doubt that there is some truth to this hypothesis. To some extent, there may be an ecologically determined imperative which has increasingly pushed environmentalists across the globe to work more closely together. As Rootes argues (this volume), '...there has developed a shared concern, grounded in a more systemic analysis of the sources of environmental ills. It would be pointless, Rootes suggests, to protect a particular species of bird, if key habitats along the migratory routes were destroyed elsewhere.

Whilst accepting that non-human nature possesses some essential properties, it must be understood that the 'environment' and its management are also concepts that are socially constructed. In short, regardless of how essential the 'environment' actually is, one must also consider the social movement, which shapes and delivers its message. (Whatmore 2002) Concepts of environment, then, are far from apolitical; rather, they are the exact opposite. As Rootes recognises, of at least equal importance is the increased collaboration between environmental non-governmental organisations over the decades. Their interplay creates new borders and frontiers leading to new and diverse geopolitical alliances, drawn upon political imaginations of a transnational character.

This is not to suggest for a moment that social movement environmentalism exclusively inhabits the political realms, below, above or around the politics of nations. Nor is it to suggest that environmental movements only pursue a politics without history. Transnational politics obviously do not occur in a void. Although 
social movements often break through realist geopolitical boundaries, as aforesaid, they are still premised on nation-state assumptions. Post-structuralism and postmodernity are rooted in structuralism and modernity. As a consequence national interpretations of green political space - and the political opportunity structures which restrict them - as we have seen in France (Hayes), Hungary (Kerènyi and Szabó) or Bosnia and Herzegovina (Fagan) are still immensely powerful as they interplay with this additional layer of increased transnational influence.

Due to the transnational currency of environmental activism, environmental politics is often mentioned in the same breath as the phrase 'global civil society' (GCS). The universal appeal of environmentalism - in all its guises - coupled with the organic characteristics of social movements, have seen environmental NGOs, and informal networks become visible parts of an ever-increasing transnational and globalised third sector. Often, all third sector political entities are all thrown into the same, almost omnipresent, conceptual basket of civil society; but the component parts of environmental social movements are impossibly varied in their contributions to transnational politics. In fact, the blurring between concepts of 'global civil society' and 'global governance', as well distinctions between third, private and public sectors are increasingly commonplace. This is why we use the term green public sphere to denote the sphere of dialogue and debate between different forms of environmentalism, based on the arguments of Torgerson (this volume).

The abilities of environmental movements to cross national boundaries leads to a multitude of outcomes. First, there are those parts of a green public space which can be understood in emancipatory terms, building regional and global networks in a manner which increases the power resources of the poor and the environmentally degraded. In the following analysis, these transnational players will be referred to as emancipatory groups (EGs). These emancipatory groups have a strong social movement dimension, as defined in the Introduction to this volume. Often, but not always, they construct themselves as separate from any notion of the state whether it be national or transnational - including green governance states - and often in rugged opposition to what they perceive to be a global neoliberal project. These EGs, often through grassroots networking, develop shared techniques, strategies, and repertoires of action alongside more localised networks and groups and they celebrate more non- 
institutional forms of organisation. It is in this manner, that the aforementioned national repertoires of resistance are shared and transmuted across borders. These organisations see a clear divide between the concepts of a global green public sphere and an environmentalised governance state; seeing themselves as part of the former, but remaining outside the latter.

Other groups - particularly powerful and well-resourced environmental NGOs - are denoted here as part of the environmental governance state (EGS). They position themselves as part of the neoliberal project of the global governance state, using limited - usually postmaterialist - interpretations of green concerns to continue to discipline societies which do not mirror their own constructions of nature, or what, in their minds, constitutes a productive and democratic civil society. These large transnational organisations, usually based in the North, construct grand narratives and systems of meaning, while giving some voice to the local, also often herding diverse forms of environmental opposition into one omnipresent story - such as climate change - gutting the stories of the local.

\section{Green Public Spheres as spaces for Ecological Emancipation}

In his article, Rootes seeks to trace the changes due to globalisation of three British organisations: the Worldwide Fund for Nature (WWF), Friends of the Earth (FoE) and Greenpeace (GP). As a crucial part of this globalisation process, Rootes sees a move away from their traditionally narrow conservation focus by WWF to incorporate the sustainable development concerns of 'the global south', bringing them closer to the political ecology perspectives of groups as FoE Whether of course this is a 'radicalisation' of goals to reflect those of the South (Rootes, this volume), or simply a means to co-opt southern agendas is open to debate; but there is no doubt that this broadening of previously narrow conservation objectives is a hallmark of transnational environmental politics in an increasingly globalised world.

In some ways the entire form of social movement environmentalism challenges the power of nation states in just as dramatic a mode as does the plutocracy of transnational corporations, though for different reasons. Although many social movement organisations - particularly the formalised component-parts of the broader 
non-institutionalised movements - are under pressure alongside the state to adopt market-based operational structures and agendas, most seem to have escaped the homogenising global corporate form. Their, often deliberate, informality, transience and translucence have also enabled them to largely escape the cost-benefit equations of corporations. As their very structure operates within the 'black' economy and polity of informal relations, the traditional sticks and carrots of nation states and corporations have not been wielded as effectively as they have been upon other social units, such as families, communities and subcultures.

The political form of social movements is suited to cross boundaries. Often boundless, anarchistic, ambiguous, many-faceted, they lack the defined edges of more institutionalised political bodies. For example, whereas governments of nation states appear increasingly unable to monitor and trace the activities of transnational corporations, social movements, due to their jelly-like structurelessness, seem more capable of 'border osmosis', of oozing through largely non-institutionalized pores in the fabric of frontiers, tracking and contesting the rapidly expanding power of transnational capital (Doyle 2005).

Regardless of global or cultural context, one of their defining characteristics is this social movement form. This structural form defies and, for the period of specific struggle, overrides barriers and borders, like class, religion, established political parties and even families, which were previously regarded as inviolate and impermeable. Environmental social movements rally and protest on a contextual basis. Strange bedfellows appear from the centre as well as from the extremes of the traditional left/right political continuum in multifarious situations. Not only this, social movement environmentalism strikes new identities, some for a fleeting moment but others more lasting. Globally mobile activists possess the 'cultural capital' of higher education (often inclusive of English language skills), 'and the social capital inherent in their transnational connections and access to resources and knowledge' (Routledge et al this volume). The ability of emancipatory environmental movements to drift through barriers can create tremendously broad coalitions of support, which can be utilised to build linkages of solidarity: the only true power resource of the powerless. 
Some environmental movements are seen as key antagonists to corporate globalisation, constantly attacking neoliberal market strategies and the largely ungoverned rampages of transnational corporations. Routledge et al's article includes a detailed analysis of the workings of a global justice network: the People's Global Action Asia (PGA). Its foremost 'collective visions' directly attack corporate control, and embrace 'a very clear rejection of capitalism' and a 'confrontational attitude, since... transnational capital is the only real policy maker'. There are a multitude of such groups and NGOs across the South - outside of the funding structures of the World Bank and wealthy nation-states - who continue to mobilise in largely structuralist fashion against the manoeuvring of global capital.

Of course, structuralist and other more radical responses targeted at the global 'other', though very apparent in many parts of the neo-colonial South, are not so appropriate in other parts of the world. In non-democratic regimes, such as Iran (Doyle and Simpson), newly emerging green NGOs provide access to the national political process for the first time to younger Iranians eager to communicate their dissatisfaction with the all-powerful regime which governs them. This process, through far from being revolutionary, is potentially emancipatory, in that it has seen the emergence of a green public sphere in Iran, which could in time be a harbinger of increasing democracy, ultimately leading to the ultimate overthrow of the ruling theocratic regime.

Nor are global resistance strategies dominant in many Northern neoliberal nationstates (though they are a component part). In parts of Europe, added to their repertoire, in given contexts, is their ability to trade on issues which are clearly within national, domestic milieu, drawing on nationalistic systems of meaning and understanding in order to boost power when appropriate. The articles within this volume by Hayes, and Kerènyi and Szabó provide excellent examples of social movement organisations utilising nationalist trump cards when it suits. In the French anti-GM protests, for example, rather than bringing the legitimacy of the state into question, activists invoked French Republican values, demanding more state intervention against the 'biological imperialism' of American companies, Pioneer and Monsanto (Hayes this volume. In a similar vein, in the Hungarian campaign against the building of the NATO facility on Zengö Hill, nationalist arguments were evoked 
by local campaigners in order to defend what was seen as a landmark important to national culture.

Within this 'bounded innovation' of national experience (Hayes), there is, however, an increasing body of evidence that campaign repertoires for resistance have strong transnational links. Greenpeace helped to introduce new tactics to France by training activists in the use of 'lock-downs' (in which activists lock on to the site they are defending using a plastic tube or other manufactured obstacle to prevent opponents from breaking the lock), which had become common in other parts of Europe. In 2004, a Catholic priest, on the Easter Zengő pilgrimage, blessed the national flag and the mountain - declaring that 'we are not giving up the mountain' (Kerènyi and Szabó this volume). This action cannot be fully understood without paying homage to the fact that this repertoire, seeking protection through sanctification, had been used before, in ways which cross the borders of other cultures, other religions and other times. The act of sanctification attaches more value to non-human nature. These passive resistance tactics, deriving their strength from within myths and rituals of established religions, reverberate with the memory of the Hindu tree-huggers of Chipko in the 1960s; later manifesting themselves in Burma with Buddhist monks ordaining trees in their attempts to halt the onslaught upon the forest; and now in Hungary, with a Catholic blessing atop Zengő Hill.

Of course, even emancipatory groups operating at the transnational level can be accused, on occasions, of not going far enough in addressing inequities, and in doing so, becoming part of the problem, rather than the solution. Doherty's research is of particular interest here in relation to EGs. By focussing on one international environmental NGO, Friends of the Earth International, with groups in 70 countries, Doherty addresses the basic issues which create friction between Northern and Southern branches in the same confederation. The case of the withdrawal of Acción Ecológica (Equador) from the FoEI confederation in 2002 is a case in point. In an attempt to address the 'divided planet' issue mentioned in the introduction of this edition, the European FoE groups were very proud of their concept of ecological space which was used to show the gross inequities of consumption patterns between North and South. But some Southern groups felt that it did not go far enough, for it did not recognise the ecological debts imposed on the South by centuries of colonial 
exploitation. This failure to address past exploitation patterns and an inability to focus on issues of redistributive justice drove a shard of ice into the very heart of the FoE confereration which, to its credit, engaged on an intense process of dialogue and debate on these issues. These tensions in EGs are constant, as they openly wrestle with their capacities to liberate, on the one hand, and to denigrate on the other. These moral dilemmas are not so evident in those large green transnational organisations we refer to here as the global green governance state.

\section{Green Governance State}

In Duffy's article on transnational environmental management in Madagascar, she argues that in the case of the South, increasingly close relationships between states, global environmental NGOs, private companies and the World Bank make it more appropriate to talk of the production of governance states, rather than the creation of a separate global civil society. NGOs like WWF and Conservation International work so closely with the interests of transnational capital and nation-states that they often become part of the same donor consortiums. In Magagascar, the Donor Consortium is comprised of USAID, the German Government, the Japanese Government, The French Government, the Swiss Government, Conservation International, WWF, Wildlife Conservation Society, and the World Bank.

In this picture, sovereignty is not a delimitation of one geographical space over another (nation-states); but is a space 'formed through a series of practices which are defined by an interaction of forces' (Duffy, this volume), including some powerful environmental NGOs. In this model, NGOs are just as much part of sovereign, global governance states as national governments.

Fagan's research on the development of the environment and civil society in postconflict Bosnia-Herzegovina tells a similar, though distinct story. Here we see the emergence of national level NGOs responding to the ecological conditionalities of donor consortiums (including some transnational NGOs) and other manifestations of global governance states. Environmental movements have not emerged through any 'heroic moments' in Bosnian politics. Rather new NGOs have emerged in top-down fashion, as a direct result of responses to the availability of largely EU funding, with 
funders ignoring the earlier history of environmentalism under the Yugoslav regime. This means that funding is mistakenly directed to the creation of civil society, which is interpreted as establishing expertise rather than an independent green public sphere. Similar outcomes occurred in Hungary (Kerènyi and Szabó) where after 1989 aid from the United States, and later from the EU, followed a similar agenda of the creation of civil society, which had the contradictory result of depoliticising environmentalism.

In these cases, environmental concerns rarely reflect the needs and aspirations of local people. Associated with the aid and donorship programs are attached conditionalities. These conditions for 'rebuilding societies' - whether it be after a war, after communism, after terrorism, or after colonialism - most usually include a pluralist, democratic system of governance, coupled with a neoliberal interpretation of the market-place. In this vein, NGOs are constructed as vehicles which can recreate and reconfigure societal relationships, replacing and ignoring social systems of the 'old order'. The old, intra-national relationships are constructed as the problem: the West or the North (whatever the construction of the polarity) is the solution. This is synonomous with 'the objective of colonial discourse', as Torgerson would have it. According to Homi Bhabba, the objective is 'to construe the colonised as a population of degenerate types on the basis of racial origin, in order to justify conquest and to establish systems of administration and instruction' (quoted in Torgerson, this volume). But, with a lack of continuous funding, one set of top-down NGOs is replaced by others better positioned to achieve success under the latest round of funding creating an orientation towards external funders and away from representing local people. There is no support offered to lasting administrative and social structures that would allow citizens to decide and implement appropriate management structures, as indigenous networks are shunned.

In a controversial article published in World Watch by Mac Chapin, the funding of three of the largest of these environmental governance organisations - WWF, Conservation International (CI) and The Nature Conservancy (TNC) - was explored in some detail (Chapin 2004). Chapin concludes that the funding arrangements of 'the big three' are intermeshed with the vested interests of transnational capital. This funding has made these organisations more dependent on large amounts of cash 
emanating from other parts of the governance state, leading to strong market competition between them. More importantly, this funding regime, has led to the decimation of local organisations. He writes:

In dealing with smaller organizations, either they tend to use their sheer heft to press their agendas unilaterally or they exclude the smaller groups altogether. A common tactic is to create new organizations out of whole cloth in foreign countries, implanting local bodies as extensions of themselves (Chapin 2004: 25).

The dominance of these large organisations is without precedence since the first emergence of the modern environmental movements in the 1960s, and its impacts are far-reaching. In Hungary, for example, Kerényi and Szabo argue that top-down environmental concerns are dominated by the reorganisation of national park management, based on a US model of public benefit foundations, rather than bureaucratic state administration. This is a long way from the mass mobilisation days of the Blue Danube movement which significantly helped to contribute to the velvet revolution in Hungary. Only since 2004 and the opening of borders with the EU has a new more transnational emancipatory green activism begun to develop, as Hungarian radicals are able to draw from repertoires and network ties with emancipatory environmental groups in other countries.

Along with a particularly apolitical version of democracy, which sees ENGOs as service-providers rather than mass mobilisers and endorsing profit-based, market solutions, a particular type of environmentalism is also constructed as a central plank of this global sovereign conditionality. It is here that the politics of neo-colonialism continues, using environmental concerns as a stick to beat local people into a submission. One way in which environmentalism is used as a continued plank of imperialism is the narrow, postmaterialist way in which it is defined.. In this vein, Duffy takes issue with Conservation International and the Wildlife Conservation Society as 'fortress conservation' organisations, meaning that they support policies that would exclude people from designated wildlife zones in order to protect nonhuman nature. This is probably the clearest indicator which separates the earlier mentioned emancipatory groups from those who are part of the green governance 
state. Emancipatory environmentalists argue that only by engaging with the subjective voices of the loca, traditional and indigenous peoples can adequate ecological management strategies be assembled; whereas organisations like CI prefer the guidance of an objective, western science, masking as apolitical and technical what is in fact a profoundly ideological position. This postmaterialist 'fortress' approach, again, sees people as the main environmental degraders, and seeks wilderness parks devoid of human imprints: 'a romanticised view of a stunning wilderness and an aura of extraordinary biodiversity' (Duffy, this volume). The three green NGOs in the Madagascar Donor Consortium are all wildlife oriented, though incredibly, they direct much national policy-making in Madagascar, both environmental and nonenvironmental, including the national poverty reduction strategy. Central to this approach are the 'the debt-for-nature swaps' and the establishment of wildlife corridors. The green voices of the East and the South are deafeningly silent here.

The emergence of this EGS - with its tightly controlled postmaterialist focus - may not actually denote trends towards democratic change at all but, rather, the construction of a state-controlled civil society, or worse, a hollow construction with civil society only marked by the clever use of nomenclature and imitation. In the cases of Iran or Burma (Doyle and Simpson) included in this edition, this public mobilisation may actually be an indicator of authoritarianism, or even totalitarianism, rather than an indicator towards democratic change. Or, alternatively, the emergence of these kinds of EGS can be seen as an indicator of free markets taking root in a given society. Even in an authoritarian regime such as Iran, the language of corporate globalisation is never far away: the reinvigoration of the third or 'civil society' sector is not really about empowering citizens; but rather, it is seen as a convenient way to 'downsize government' and reduce its direct responsibilities in emvironmental policymaking.

These environmental governance organisations, with their increasing dominance of the green political space, are increasingly building and selling grand environmental narratives with global reach. Climate change is the current theme used most often in the ecopolitical marketplace. These stories are the songlines of ecological conditionality, mapping out the co-ordinates that determine which groups shall be included in agenda-setting and decision-making; determining those who will be 
funded; selecting those who shall be corporatised into the global governance state, and relegating those who shall remain on the non-institutionalised outer. Rootes writes of the new urgency with which climate change has been embraced, as the story of climate has become such a large metanarrative that it almost embraces all elements of environmental discourse. He quotes its WWF's UK Chairman, Christopher Ward as follows:

...today, WWF's work is much wider and more complex. You cannot save the polar bear if the Arctic ice cap on which it lives melts away through global arming... WWF views climate change as the single greatest threat facing the planet... we have all joined the list of endangered species (Rootes, this volume).

Climate change is an important, global problem and despite the existence of factions of scientists still denying the problem, it seems one side - the side advocating the role of humans in creating global climate change - is now gaining a firm upper hand. The ascendancy has been gained by a combination of factors, including: i) the results of most forms of scientific experimentation in relation to, for example, the melting of ice-caps and rising sea level seem to be pointing this way; and ii) the pro-climate position - after an initial period of rejection - is now being championed, more and more, by powerful political and business interests at both the national and international levels, most particularly in the North (see Matthews and Paterson 2005). This recent embrace by parts of the business community, in part, can be linked to the ease with which climate change arguments can justify business-as-usual approaches, as well as their propensity to be mustered to promote the growth of the nuclear industry across the globe.

Despite this dominant position in the affluent world, many environmentalists in the South regard climate change as receiving excessive attention. It is seen as a matter endorsed by affluent world, western, science, and then utilised as an environmental security issue to control the less affluent from pursuing the very path of development which the minority world has pursued without restraint since the industrial revolution. In the South, it is widely argued that there are more urgent environmental issues pertaining to the atmosphere that (Doyle and Risely 2007) revolve around issues of air pollution and their direct impacts upon human health. These issues are more 
reminiscent of those which evolved in the North during the 1970s, though in the case of the South these issues are exacerbated due to the size and rapidity of industrialisation, coupled with a profound lack of environmental and health infrastructure. In Friends of the Earth International some southern groups asked whether desertification and deforestation received less attention than climate change because their effects were mainly in the South.

A critical view of the predominant climate change discourse is that it takes much of the politics - the conflict - out of environmental resource issues, providing a polite filter between human action and human consequence; taking the direct and instrumental power relationships out of the equation. It is no longer people against people: the exploiters versus the exploited, or in this case, the polluters versus the polluted. Rather, although people are still the initiators, they are cast in a far more oblique light, often unwittingly setting off a calamitous, climactic punishment for all. A force of nature is, in the end, the nemesis, whereas the initiators, the environmental degraders, are in relative safety, at a convenient one-step removed from the atrocities inflicted upon the many. Also, by constructing the concept of an environmental 'day of judgment' for all, all humans (all creation) are cast equally as victims; not differentiating between the perpetrators and fatalities.

\section{Conclusion}

Under neoliberal regimes, environmentalism is commonly a central plank in the construction of a new world order (both in Eastern Europe as well as in the South) pursued by networks and consortiums of transnational corporations, financial institutions, powerful, Northern green NGOs, and other transnational and national elites. These consortiums discipline populations into accepting conditionalities attached to aid and restructuring packages which include neoliberal markets; apolitical pluralist governance with its concomitant down-sized bureaucracy; and a particularly limited and toothless version of what constitutes environmentalism. In authoritarian regimes, it simultaneously denotes a politics of dissent and state authority.

But, of course, transnationalisation in a globalised world is multifarious and multidirectional. There is also dramatic evidence that in more recent times, Southern 
movements are increasingly driving the global green movement agenda, with many Northern NGOs taking a subservient role for now. For the flow of history is a mirror opposite in the green movements of the minority world. Many movements in the North, began as postmaterialist movements, interested in trees, parks and threatened species, but are gradually coming to terms with the fact that people are also part of the environmental equation, they are not separate from nature. The beginnings of environmental justice and democracy movements are evolving in the North. This has occurred due largely to the amplified power of Southern movements in the last decade or so (Princen and Finger 1994: 8).

It would be vacuous, however, to suggest that power moves equally both ways, like the tide, and that in the end some form of global balance will be struck. As there is no such thing as a free market, or a free lunch, there is also no such thing as a free political space. The amorphousness and structurelessness of social movements (alongside their cyberspace equivalent in the supposedly equally structurelessness Internet) may ultimately deliver results to the more powerful players.

Currently, however, a study of transnational environmental politics is more a celebration of differences than similarities: more evidence of the fact that there are many environmental movements across the earth rather than one. Regardless of very recent trends which suggest an increasing interplay between environmental movements across the world, however, the empirical reality is different. In fact, as is evidenced in all of the articles in this edition, profound differences in ideology and focus, rather than similarities, define the environmental movement experience between North and South, rather than cross-boundary, shared political activities/identities. Some environmental organisations - often part of a green governance state - will seek to globalise environmentalism through disciplining the local into a carefully constructed and restricted version of the global. These organisations will become increasingly moneyed, and progressively more powerful, and their politics of ecological conditionality, regardless of the honour of their intentions, can only be understood within a frame of postcolonialism. The majority of environmental movements across the globe, however, will persist in their varied attempts at environmental emancipation. In their salutation of diversity, and their attempts to resist the all-powerful but understandable urge to overly homogenise 
opposition, they will continue to forge resilient societal alternatives, emerging from a continued respect and reverence for diverse localised experiences within the multitude of ecological communities. Torgerson writes:

A green politics for a divided planet depends on an expansion of the green public sphere, but such a politics is necessarily a divided politics in the sense that it neither anticipates or achieves an undifferentiated unity. The divisions, however, do not necessarily spell a lack of connections. A green politics for a divided planet, indeed, depends upon interconnected spaces distinguished by intimations of, as well as approximations to, commonalities capable - at a minimum - of making disagreements somehow meaningful' (Torgerson this volume).

\section{References}

Bhabba, H. (1990) 'The other question: Difference, discrimination and the discourse of colonialism,' in R. Ferguson, M. Gever, T. Minh-Ha, C. West, eds Out There: Marginalization and Contemporary Cultures (Cambridge, MA: The M.L.T. Press), pp. $71-87$.

Calvert, P. and S. (1999) The South, The North and the Environment, Pinter: London and New York.

Dahl, R. (1969) 'The Concept of Power', in R. Bell, D. Edwards, R. Harrison Wagner (eds) Political Power: A Reader in Theory and Research, Free Press, New York.

Chapin, M. (2004) 'A Challenge to Conservationists,' World Watch, November/December 2004, World Watch Institute, pp. 17 - 31.

Doyle, T. (2005) Environmental Movements in Majority and Minority Worlds: A Global Perspective, N.J., New York and London: Rutgers University Press. 
Doyle, T. and Risely M. (2007, in press) Crucible for Survival: Environmental Justice and Security in the Indian Ocean Region, Rutgers University Press, N.J., New York and London.

Doyle and McEachern $(1998,2001)$ Environment and Politics, London and New York: Routledge.

Grove, R. (1995) Green Imperialism: Colonial Expansion, Tropical Island Edens, and the Origins $f$ Environmentalism, 1600 - 1860, Cambridge: Cambridge University Press.

Lukes, S. (1974) Power: A Radical View, London, Macmillan.

Martinez-Alier, J. (2004) 'Ecological Distribution Conflict and Indicators of Sustainability,' English translation in Revista ibero-americana de econom ía ecológica, no. 1, 1994, pp. $21-31$.

Matthews, K. and Paterson, M. (2005) 'Boom or Bust?: The Economic Engine Behind the Drive for Climate Change Policy', Global Change, Peace and Security, 17,1: pages to follow.

Princen, T. and Finger, M., eds (1994) Environmental NGOs in World Politics, London: Routledge.

Ward, B. and Dubos, R. (1972) Only One Earth: The Care and Maintenance of a Small Planet (New York: Norton).

Whatmore, Sarah (2002) Hybrid Geographies: natures cultures spaces, London: Sage. 